УДК 316.7 (06)

$10.17213 / 2075-2067-2021-1-77-84$

\title{
СТУДЕНЧЕСКАЯ МОЛОДЕЖЬ КАК ОБЪЕКТ И СУБЪЕКТ ГЕНДЕРНОЙ СТЕРЕОТИПИЗАЦИИ
}

\author{
(C) 2021 г. Н. Г. Тищенко , И. А. Тищенко**, С. В. Чернецкая
}

\section{"Ростовский государственный медицинский университет, г. Ростов-на-Дону, Россия "Шахтинский автодорожный институт (филиал), Южнно-Российский государственный политехнический университет (НПИ) имени М. И. Платова, г. Шахты, Россия}

Цель исследования состоит в социологическом анализе концепта «студенческая молодежь» как объекта и субъекта гендерной стереотипизации, что позволяет рассматривать современное студенчество как движущую силу социокультурных изменений в обществе, которому (студенчеству) принадлежит лидирующая роль в ближайшем будущем и чьи ценностно-нормативные представления, гендерные установки станут определяющиими в российском соииокультурном пространстве.

Методологическую базу исследования представляют классические сочиологические теории социального действия (М. Вебер, Т. Парсонс), сочиальной идентификации (Г. Тэджфел, Дж. Тернер и др.), современнье конщепщии молодежи, теория К. Манхейма о значении поколений в сочиальных трансформациях. В работе использовались общенаучные методы исследования (аналитический, системный, компаративный анализы) и методы сочиологического исследования (анализ материалов, документов, анкетирование и др.).

Результаты исследования. В русле синтезирующего подхода современное студенчество рассмотрено как многокачественное понятие в единстве его субъективного и объективного, сочиального и индивидуального, внешних и внутренних связей; дано авторское определение концепта «студенческая молодежь», обоснована ее лидирующая роль в сочиокультурной эволюичи российского общчества.

Перспективы исследования. Изучение иенностно-нормативных представлений, гендерных стереотипов современной студенческой молодежи различных типов поселения и профиля образования позволят прогнозировать характер динамики транформирующегося российского общества, выявить перспективы его модернизации.

Ключевые слова: студенческая молодежь; гендерная стереотипизация; субъектные свойства студенчества; социокультурная эволюиия общества.

\section{YOUNG STUDENTS AS AN OBJECT AND SUBJECT OF GENDER STEREOTYPING}

(C) 2021 Yu. G. Tishchenko ${ }^{*}$, I. A. Tishchenko **, S. V. Chernetskaya ${ }^{* *}$

"Rostov State Medical University, Rostov-on-Don, Russia

*"Shakhty Road Institute (branch), Platov South Russian State Polytechnic University (NPI), Shakhty, Russia

The aim of the study is to analyze the concept of «young students» as an object and subject of gender stereotyping, which allows us to consider modern students as a driving force of socio- 
cultural changes in society that (students) has a leading role in the near future and whose valuenormative ideas, gender attitudes are going to become decisive in the Russian socio-cultural space.

The methodological basis of the research is represented by the classical sociological theories of social action (M. Weber, T. Parsons), social identification (G. Tagefel, J. Turner, etc.); modern concepts of youth, $K$. Manheim's theory on the importance of generations in social transformations. General scientific research methods (analytical, system, comparative analysis) and methods of sociological research (analysis of materials, documents, questionnaires, etc.) were used in the research.

Results of the research. In line with the synthesizing approach, modern students are considered as a multi-quality concept in the unity of its subjective and objective, social and individual, external and internal relations; the author's definition of the concept «young students» is given, its leading role in the socio-cultural evolution of Russian society is justified.

Research prospects. The study of value-normative ideas, gender stereotypes of modern young students of various types of settlement and educational profile will allow us to predict the nature of the dynamics of the transforming Russian society, to identify the prospects for its modernization.

Key words: young students; gender stereotyping; subjective properties of students; sociocultural evolution of society.

Современные глобальные изменения, происходящие во всех сферах жизнедеятельности российского общества и затрагивающие каждого отдельного человека, не могут не сопровождаться и изменениями в общественном сознании. Процесс изменения традиционных структур в области экономики, государственного устройства достаточно сложен, но не менее сложен и процесс изменения сложившихся социальных норм, стереотипов, установок, мировоззрения. Сегодня все чаще звучат слова о необходимости изменения привычных стереотипов мышления, тормозящих процесс реформирования современного общества и «не вписывающихся» в рамки инновационных парадигм. Большие надежды в «ломке стереотипов прошлого» возлагаются, безусловно, на молодежь, именно на студенческую молодежь, как наиболее образованную, политически и социально-экономически грамотную, способную не только наследовать, трансформировать сложившиеся общественные отношения, но и создавать качественно новые, более прогрессивные модели поведения, способствующие гармонизации отношений в российском обществе. Уже в ближайшем будущем, согласно К. Манхейму [1], ценностно-нормативные представления, гендерные установки современной студенческой молодежи станут определяющими в российском социокультур- ном пространстве. В связи с этим проблема стереотипизации сознания современной студенческой молодежи приобретает особую значимость и актуальность.

Гендерной стереотипизации, как известно, подвержены все половозрастные категории людей, независимо от их индивидуальных особенностей - каждый человек с момента своего рождения становится объектом воздействия гендерного пространства: в традиционной культуре приняты определенные, в зависимости от пола новорожденного, родильные обряды; цвета одежды, колясок, набор игрушек и др. также определяются полом ребенка. В процессе первичной социализации детей ее агенты (семья и ближайший социум, различные учреждения системы образования, культура в целом) формируют в их сознании представления о том, какими должны быть «истинный мужчина» и «истинная женщина», как они должны одеваться, вести себя, чем заниматься и т.д., то есть формируют определенные гендерные нормы, модели поведения, которые впоследствии поддерживаются и закрепляются с помощью различных культурных (например, стереотипов в искусстве, СМИ) и социальных механизмов (например, право). Таким образом, гендерная стереотипизация не только фиксирует биологические различия полов, но и создает дополнительные - социальные и культурные - 
половые различия, используя их как основу для дифференциации социальных статусов и ролей мужчины и женщины в современном обществе.

Гендерная стереотипизация «накладывается» на процессы гендерной социализации; оба процесса взаимосвязаны между собой, но не тождественны. Приобретение, усвоение и закрепление гендерных характеристик, норм, социально принятых моделей поведения, социальных установок, соответствующих социокультурным экспектациям в отношении мужчин и женщин, обозначим гендерной социализацией. Она включает в себя всю совокупность процессов, связанных с формированием гендерной идентичности и освоением гендерных ролей.

Особенность гендерной социализации заключается в том, что в ее основе лежит четкая дифференциация культурных образцов и стандартов поведения и отношений, ценностей, социальных навыков, личностных характеристик, связанных с разделением людей на гендерные группы. Гендерная социализация в большей степени связана с усвоением нормативных образцов гендерного проявления личности, которые (образцы), в сущности, представляют собой не что иное как гендерные стереотипы. Последние детерминируют процесс социальной перцепции и оказывают существенное влияние на активное конструирование социальной реальности с использованием заложенной в них информации. И если гендерная социализация продолжается на протяжении всей жизни человека, то гендерная стереотипизация ограничена возрастными стадиями, завершающимися примерно в возрасте 30 лет, когда гендерные установки и стереотипы приобретают устойчивый и ригидный характер.

Канадским исследователем Ж. Годфруа выделены три условных этапа стереотипизации и формирования социальных установок в процессе социализации личности [2].

Первый этап приходится на детский возраст и длится до 12 лет. Усваиваемые в этот период стереотипы являются, в сущности, результатом социального научения: ребенок воспринимает и усваивает мнения и убеждения, разделяемые прежде всего родителями, подражает и идентифицирует себя с родителем своего пола. Те (родители) в основном используют внушение и убеждение в качестве основных способов воздействия на ребенка. Именно в семье передаются гендерные предписания и закладываются основные гендерные стереотипы. К ним относятся те или иные психологические характеристики, которые приписываются ребенку в зависимости от его биологического пола (гендерные правила переживания и выражения эмоций полностью соответствуют социально-половым стереотипам маскулинности или феминности). С детства закрепляются гендерные предписания и стереотипы в отношении семейных и профессиональных ролей (мужчинам предписывается материальное обеспечение семьи, профессиональная успешность; для женщины более значимыми являются роли матери, домохозяйки). Категоризация по гендеру, согласно В. МакКену и С. Кесслеру, не является добровольной и не зависит от внутреннего выбора индивида, поскольку носит принудительный характер [3].

Получая информацию о способах гендерной репрезентации от представителей разных гендеров, дети склонны воспроизводить только те модели, которые соответствуют их гендерной идентичности. Индивидуальная концепция феминности или маскулинности закладывается в раннем детстве и остается практически неизменной в течение всей жизни.

Второй этап формирования стереотипов и установок начинается в подростковом возрасте, примерно с 12 лет, и продолжается до возраста ранней молодости - 20 лет. На этом этапе установки структурируются и приобретают более конкретную форму; принятие гендерных стереотипов непосредственно связано с усвоением гендерных ролей.

В пубертатном возрасте с ослаблением авторитета родителей именно сверстники становятся наиболее важными субъектами для подражания и определения «норм» жизни. Подростки стремятся быть «принятыми» прежде всего сверстниками, что непосредственно связано с усвоением разделяемых в той или иной группе гендерных норм и стереотипов.

При восприятии гендерных стереотипов люди проявляют конформизм, подстраиваясь под общепринятые гендерные нормы. В обществе, как правило, гендерно типичные формы поведения одобряются, а гендерно 
нетипичные порицаются. Стремление получить внутригрупповую поддержку и поощрение подталкивает человека к реализации поведения, которое соответствует биологическому полу и разделяемым в группе стереотипам и ожиданиям. В противном случае, когда ожидаемое и реализуемое индивидом поведение не соответствует его внутренним потребностям, возникает гендерно-ролевой конфликт.

На третьем этапе, длящимся с 20 до 30 лет, гендерные стереотипы и установки «кристаллизируются» и прочно закрепляются в системе убеждений индивида; после 30 лет они практически не меняются, приобретают стабильность и фиксированность. Данный период в жизни человека охватывает, как правило, время обучения, приобретения профессиональных знаний, умений и навыков. Важнейшими агентами социализации, в том числе и гендерной, становятся учебные заведения и различные социальные организации.

Одним из значимых факторов гендерной стереотипизации является возраст стереотипизируемого: гендерные стереотипы, по мнению социологов, в наибольшей степени распространены в молодежной среде [4]. Именно в сознании и социальной активности студенческой молодежи наиболее отчетливо отражается изменение гендерного порядка, ценностно-нормативных, институциональных и структурных оснований российского общества.

Студенческая молодежь представляет собой значительную по численности часть российской молодежи. По данным Росстата, в 2019 году в вузах (229 государственных и 495 муниципальных) Российской Федерации обучалось 4,1 млн. студентов [5].

В настоящее время в отечественной социологической науке существуют различные точки зрения на студенческую молодежь, выделение ее характерных признаков, особенностей ее субъектной деятельности, но на наш взгляд, наиболее полное определение понятия «студенчество» дано А.М. Прохоровым, который понимает под ним социально-демографическую группу учащихся высших учебных заведений, «характеризующуюся определенной численностью; половозрастной структурой; территориальным распределением; определенным обществен- ным положением, ролью и статусом; особой фазой, стадией социализации (студенческие годы), ... которая характеризуется определенными социально-психологическим особенностями» [6, с. 1277].

В качестве последних выделены следующие:

1) возрастные характеристики студенческой молодежи, границы которых определяются достаточно широко - от 16 лет до 30. Данная группа молодежи включает в себя не только юношей и девушек 18-24 лет и так называемых «молодых взрослых» 25-30 лет, становление личности которых и формирование системы жизненных ценностей и приоритетов в процессе первичной социализации уже завершилось, но и 16-17-летних молодых людей, у которых процесс перехода от первичной социализации к вторичной только начинается;

2) особый социальный (престижный) статус, т.к. студенчество является наиболее образованной, эрудированной частью молодежи, что, несомненно, выдвигает его в число передовых групп и предопределяет формирование специфических черт психологии студенческого возраста;

3) положение студенчества в социокультурной эволюции детерминирует его роль и качества: студенческая молодежь, с одной стороны, усваивает и накапливает имеющийся социальный и социокультурный опыт, с другой стороны - впитывая «как губка» все новое, генерирует прогрессивные идеи, ценности, виды деятельности, реализует особые социальные функции: воспроизводственную, трансляционную, инновационную [7];

4) общие цели, устремления, установки в получении высшего образования, единый характер труда, образа жизни способствуют выработке у студенчества сплоченности, проявляющейся в многообразии форм их коллективной деятельности, формируют определенный стиль группового поведения, социального самочувствия и т.д.;

5) достаточно высокая и стабильная мобильность студенчества, обусловленная тем, что состав данной группы молодежи ежегодно меняется;

6) возможность социального продвижения, поскольку вуз является одним из средств социального продвижения молодежи, его объективной предпосылкой; 
7) высокая интенсивность общения студентов с различными социальными образованиями общества, «накопление социального и социокультурного опыта в процессе социализации и социальной адаптации в условиях самостоятельной жизнедеятельности, включения во “взрослую” жизнь» [8, с. 157-166].

Все вышеперечисленные особенности (признаки) тесно взаимосвязаны, ни одна из них отдельно взятая не исчерпывает сущность и содержание студенчества.

Мы придерживаемся определения современного студенчества как специфической социально-демографической группы молодежи, включенной в институт высшего профессионального образования, характеризующейся определенными социально-психологическими особенностями, особыми положением, ролью и функциями в социокультурной эволюции и обладающей повышенным инновационным потенциалом [9].

«В целом для понимания молодежи в ее целостности наиболее продуктивен синтезирующий подход, позволяющий рассматривать студенчество в единстве его субъективного и объективного, социального и индивидуального, внешних и внутренних связей, интегрирующий его универсальные и уникальные признаки и дефиниции.

В русле такого подхода молодежь рассматривается как многокачественное понятие. Сущность, основное содержание, то, что отличает студенческую молодежь от других социальных образований и составляет основу ее существования, детерминируется объективными и субъективными факторами. К первой группе относятся условия, не зависящие от сознания и самосознания молодежи, и внутренние установки, сформированные в процессе интериоризации, отражающие объективные социокультурные условия, ставшие достоянием субъекта. Ко второй группе относятся условия, зависящие от активности самого субъекта, его внутреннего мира, субъективного осознания объективной действительности» [7, с. 62-63].

Сегодняшние студенты входят в ту поколенческую когорту российской молодежи, которой, согласно теории К. Манхейма о роли поколений в общественных процессах и трансформациях, «принадлежит лидирующая роль в будущем (с периодом упрежде- ния 15-18 лет), но именно в настоящее время формируются основы для реализации этой роли» [1, с. 444-461].

Студенческий возраст приходится на период поздней юности или начало взрослости (от 18 до 23-25 лет), как заключительный этап перехода от детства к взрослости.

В юношеском возрасте происходит становление личности, связанное с постоянным выбором: системы ценностей, профессии, партнера по браку и т.д. В это время формируются и развиваются наиболее важные личностные образования, такие как «Я-концепция» и идентичность, самоопределение, мировоззрение, принимаются жизненно важные решения. Фундаментальным психологическим новообразованием юношеского возраста становится интенсивное формирование системы ценностей, с образованием которой происходит активное осмысление человеком окружающей действительности и собственного места в ней [10].

В студенческие годы молодые люди «созревают», т.е. становятся взрослыми не только физиологически, но и в социально-психологическом отношении: они уже в полной мере несут ответственность за свои деяния, поступки, свою жизнь, оказываются перед объективной необходимостью осуществления ряда важных жизненных выборов (профессии, брачного партнера и др.). Приоритетной целью становится не столько «поиск себя», самоопределение, сколько самореализация в обществе. «Молодежь входит в ткань социальных отношений, формирует собственную систему ценностей, ... жизненных целей и перспектив, осуществляет первые самостоятельные жизненные выборы и решения» $[7$, с. 68$]$.

Сущность студенческой «молодежи как субъекта есть постоянное изменение: это не только становление для себя, самостановление, саморазвитие, это постоянное продуцирование, развертывание своей субъектности, поиск и формирование нового (культуры, видов и форм социальной деятельности, ролей, статусов, идеалов)» [7, с. 69].

Субъектные свойства современного студенчества позволяют трансформировать не только сложившиеся общественные структуры в соответствии с реалиями окружающей действительности, но и видоизменить 
характер общественных отношений, в том числе и гендерных, являющихся важнейшим аспектом социальной и культурной жизни социума, определяющих его культурную эволюцию и выступающих в качестве основного параметра его цивилизованности.

Современное студенчество, будучи наиболее восприимчивым к происходящим социальным переменам, новым идеям и ценностям, представляет собой движущую силу социокультурных изменений в обществе, поэтому динамика в гендерном порядке последнего, трансформация его ценностно-нормативных, институциональных и структурных оснований наиболее отчетливо должны отражаться в сознании студенческой молодежи, что обусловило выбор ее в качестве объекта нашего исследования.

В заключение следует отметить, что изучение гендерных стереотипов современной студенческой молодежи, ее ценностно-нормативных представлений, установок дает уникальную возможность прогнозировать характер динамики транформирующегося российского общества, выявить перспективы его модернизации.

\section{Литература}

1. Манхейм K. Диагноз нашего времени/ Пер. с нем. и англ. - М.: Юрист, 1994. C. 444-461.

2. ГодфруаЖ. Что такое психология. В 2-х т. / Пер. с франц. - М.: Мир, 1992. T.2. $-363 \mathrm{c}$.

3. Women's Studies Encyclopedia. Ed. Tierney H. - N.Y. Peter Bedrick Books, 1991. - 1607 p.

4. Рябова Т.Б. Стереотипы и стереотипизация как проблема гендерных исследований [Электронный ресурс] // Личность. Культура. Общество. - Т. V. - Вып. 1-2 (15-16). С.120-139. / Гендер. Политический дискурс. Сайт Татьяны Рябовой. - Режим доступа: http://w3.ivanovo.ac.ru/alumni/riabova/ stereotype.htm.

5. Численность студентов и количество мест в вузах в России. Инфографика [Электронный ресурс]. - Режим доступа: https://aif.ru/society/education/chislennost studentov_i_kolichestvo_mest_v_vuzah_v_ rossii_infografika.
6. Прохоров А. М. Советский энциклопедический словарь. - М.: Советская энциклопедия, 1984. - С. 1277.

7. Явон С. В. Динамика социальной роли молодежи: гендерный подход: дис. ... д-ра социол. наук: 22.00.04 / Явон Снежана Владимировна. - М.: МГПИ, 2010. - 405 с.

8. Щеглова С.Н. Определение границ перехода от детства к молодости и от молодости к взрослости / С.Н. Щеглова // Молодежь - 97: надежды и разочарования. - М., 1997. - С. 157-166.

9. Тищенко Ю.Г. Гендерные стереотипы современной студенческой молодежи: социологический анализ: автореф. дис. ... канд. социол. наук. - Ставрополь, 2014. - 31 с.

10. Кон И.С. Психология ранней юности. - М.: Просвещение, 1989. — 255 с.

\section{References}

1. Manhejm K. Diagnoz nashego vremeni [The diagnosis of our time] / Per. s nem. i angl. Moscow: Jurist, 1994. - Pp. 444-461.

2. Godfrua Zh. Chto takoe psihologija. V 2-h t. [What is psychology? In 2 vols.] / Per. s franc. - Moscow: Mir, 1992. - Vol. 2. - 363 p.

3. Women's Studies Encyclopedia. Ed. Tierney H. - N.Y. Peter Bedrick Books, 1991. - $1607 \mathrm{p}$.

4. Rjabova T. B. Stereotipy i stereotipizacija kak problema gendernyh issledovanij [Stereotypes and stereotyping as a problem of gender studies] [Jelektronnyj resurs] // Lichnost'. Kul'tura. Obshhestvo [Personality. Culture. Society]. - Vol. V. — Issue 1-2 (1516). - Pp. 120-139. / Gender. Politicheskij diskurs. Sajt Tat'jany Rjabovoj [Gender. Political discourse. Website of Tatyana Ryabova]. - URL: http://w3.ivanovo.ac.ru/ alumni/riabova/stereotype.htm.

5. Chislennost' studentov i kolichestvo mest v vuzah v Rossii. Infografika. Infographics [The number of students and the number of places in universities in Russia] [Jelektronnyj resurs]. - URL: https://aif.ru/society/education/ chislennost_studentov_i_kolichestvo_mest_v_ vuzah_v_rossii_infografika.

6.Prohorov A.M. Sovetskijjenciklopedicheskij slovar' [Soviet Encyclopedic Dictionary]. Moscow: Sovetskaja jenciklopedija, 1984. P. 1277. 
7. Javon $S . V$. Dinamika social'noj roli molodezhi: gendernyj podhod: dis. ... d-ra sociol. nauk [Dynamics of the social role of youth: gender approach: Dr. Sci. (Sociology) diss.]: 22.00.04 / Javon Snezhana Vladimirovna. - Moscow: MGPI, 2010. - $405 \mathrm{p}$.

8. Shheglova S.N. Opredelenie granic perehoda ot detstva $\mathrm{k}$ molodosti i ot molodosti $\mathrm{k}$ vzroslosti [Determining the boundaries of the transition from childhood to youth and from youth to adulthood] / S. N. Shheglova // Molodezh' 97: nadezhdy i razocharovanija [Young people - 97: hopes and disappointments]. Moscow, 1997. - Pp. 157-166.

9. Tishhenko Ju. G. Gendernye stereotipy sovremennoj studencheskoj molodezhi: sociologicheskij analiz: avtoref. dis. ... kand. sociol. nauk [Gender stereotypes of modern student youth: a sociological analysis: abstract. Ph. D. Sci. (Sociology) diss.]. - Stavropol', 2014. - $31 \mathrm{p}$.

10. Kon I.S. Psihologija rannej junosti [Psychology of early youth]. - Moscow: Prosveshhenie, 1989. - $255 \mathrm{p}$.

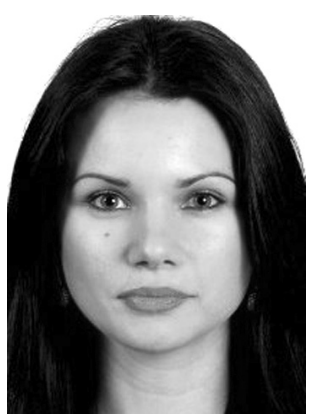

Тищенко Юлия Геннадьевна - кандидат социологических наук, специалист отдела организации учебного процесса учебного управления Ростовского государственного медицинского университета Министерства здравоохранения Российской Федерации.

Tishchenko Yulia Gennadievna - Candidate of Sociological Sciences, Specialist of the educational process organization Department, Rostov State Medical University of the Ministry of health of the Russian Federation.

344022, г. Ростов-на-Дону, пер. Нахичеванский, 29

29 Nakhichevansky st., 344022, Rostov-on-Don, Russia

E-mail: Yuliatisss@yandex.ru 


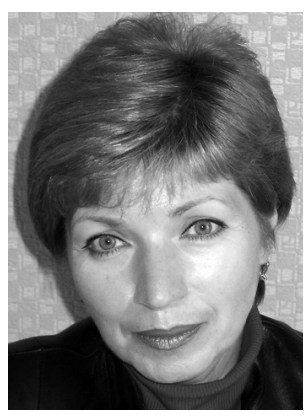

Тищенко Ирина Александровна - доцент, кандидат педагогических наук, доцент кафедры «Экономика и управление» Шахтинского автодорожного института (филиала) Южно-Российского государственного политехнического университета (НПИ) имени М.И. Платова.

Tishchenko Irina Aleksandrovna - Associate Professor, Candidate of Pedagogical Sciences, Associate Professor of «Economics and Management» Department, Shakhty Road Institute (branch), Platov South Russian State Polytechnic University (NPI).

346500, г. Шахты, пл. Ленина, 1

1 Lenina sq., 346500, Shakhty, Russia

E-mail: lingvan@yandex.ru

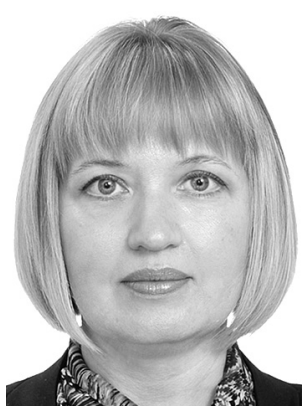

Чернецкая Светлана Владимировна - кандидат философских наук, доцент кафедры «Экономика и управление» Шахтинского автодорожного института (филиала) Южно-Российского государственного политехнического университета (НПИ) имени М. И. Платова.

Chernetskaya Svetlana Vladimirovna - Candidate of Philosophical Sciences, Associate Professor of «Economics and Management» Department, Shakhty Road Institute (branch), Platov South Russian State Polytechnic University (NPI).

346500, г. Шахты, пл. Ленина, 1

1 Lenina sq., 346500, Shakhty, Russia

E-mail: svetlana_chernec@inbox.ru 